\title{
Unusually extensive networks of vocal recognition in African elephants
}

\author{
KAREN MCCOMB*†, CYNTHIA MOSS $†$, SOILA SAYIALEL $\dagger \&$ LUCY BAKER*† \\ *Experimental Psychology, School of Biological Sciences, University of Sussex \\ $\dagger$ Amboseli Elephant Research Project, African Wildlife Foundation \\ (Received 14 September 1999; initial acceptance 26 October 1999; \\ final acceptance 28 January 2000; MS. number: 6351)
}

\begin{abstract}
Research on acoustic communication has often focused on signalling between territorial individuals or static neighbouring groups. Under these circumstances, receivers have the opportunity to learn to recognize the signals only of the limited number of conspecifics with which they are in auditory contact. In some mammals, however, social units move freely with respect to one another and range widely, providing individuals with opportunities to learn to recognize the signals of a wide range of conspecifics in addition to those of their immediate neighbours. We conducted playback experiments on African elephants, Loxodonta africana, in Amboseli National Park, Kenya, to determine the extent to which adult female elephants, which have a highly fluid social system, can recognize others in the population through infrasonic contact calls. Female elephants could distinguish the calls of female family and bond group members from those of females outside of these categories; moreover, they could also discriminate between the calls of family units further removed than bond group members, on the basis of how frequently they encountered them. We estimated that subjects would have to be familiar with the contact calls of a mean of 14 families in the population (containing around 100 adult females in total), in order to perform these discriminations. Female elephants thus appear to have unusually extensive networks of vocal recognition, which may prove to be typical of long-lived species that have both fluid social systems and the means for long-distance vocal communication.
\end{abstract}

() 2000 The Association for the Study of Animal Behaviour

It is now widely recognized that communication involving long-distance signalling is best viewed as occurring within a network, where any signallers and receivers that are within range of each other have the potential to interact (McGregor 1993; McGregor \& Dabelsteen 1996). Studies of acoustic communication networks have focused on singing in birds, where territorial males broadcast information about their status that is available not only to the intended receiver but also to many receivers extraneous to the communication event (McGregor \& Dabelsteen 1996). The emphasis that this puts on information gathering by 'eavesdropping' has had important implications for empirical studies of male-male assessment and mate choice (e.g. Otter et al. 1999). However, applying a communication networks approach to longdistance signalling also has consequences for studies of social recognition. These consequences are likely to be particularly far-reaching in mammals with fluid social

Correspondence: K. McComb, Experimental Psychology, School of Biological Sciences, University of Sussex, Falmer, Brighton BN1 9QG, U.K. (email: karenm@biols.susx.ac.uk). C. Moss and S. Sayialel are at the Amboseli Elephant Research Project, African Wildlife Foundation, Box 48177, Nairobi, Kenya.

0003-3472/00/061103+07 \$35.00/0 systems, in which the unusually high encounter rates that individuals have with conspecifics should interact with long-distance signalling abilities to increase considerably the opportunities that receivers have for learning to recognize the vocalizations of other individuals in the population.

Within a communication network that involves longdistance signalling, receivers may be provided with opportunities for learning to recognize the signals of conspecifics that are widely separated from them. However, for territorial species such as many birds and some mammals, this still places a fairly restrictive upper limit on the number of conspecifics whose signals can be learnt, set by the maximum distance over which the signal involved can propagate in an intelligible form. In certain mammals, social systems are highly fluid with individuals and social units moving freely with respect to each other and ranging widely. Under these circumstances, because individuals are passing through the signalling ranges of a much larger number of conspecifics, they have opportunities to learn to recognize many more signallers than just their immediate neighbours. Provided that mental capacities for storing information on the 
identity of conspecifics' signals are adequate, individuals could therefore become familiar with the signals of many different conspecifics that form part of a widespread population. The question of whether communication provides social connections between individuals on this much larger scale has never been empirically investigated.

Mammal species that have highly fluid social systems and also use long-distance signals for social communication include certain primates (e.g. chimpanzees, Pan troglodytes: Nishida \& Hiraiwa-Hasegawa 1986), cetaceans (e.g. killer whales, Orcinus orca: Ford 1991) and the subjects of our study, African elephants, Loxodonta africana. Of the two sexes of African elephants, females are the more social (Moss \& Poole 1983; Poole 1995). Close social relationships exist between members of a family unit (usually composed of adult females that are matrilineal relatives and their immature offspring) but also appear to link bond groups of families that associate frequently and often greet one another when they meet (Moss \& Poole 1983; full details in Methods). Family units move freely with respect to one another, ranging widely and frequently coalescing with other family units in the population as they move and feed, thus exhibiting high levels of social fluidity (Moss \& Poole 1983). Females communicate using a variety of calls that have infrasonic fundamental frequencies $(15-35 \mathrm{~Hz})$, the low frequencies of which should be particularly resilient to attenuation with distance (Poole et al. 1988); these calls are referred to as 'infrasonic', although harmonics of the fundamental frequency do extend into the audible frequency range, and can be detected by elephants several kilometres from the caller (Langbauer et al. 1991; Garstang et al. 1995; Larom et al. 1997a, b).

The infrasonic call most regularly used by female elephants for long-distance communication with social companions is the contact call (Poole et al. 1988). Contact calls, which have a mean peak fundamental frequency of $21 \mathrm{~Hz}$ and typically last 4-5 s (K. McComb, personal observation) are used by social companions to stay in contact when visually separated (Poole et al. 1988). In a population of elephants in Amboseli National Park, Kenya, with known life histories and ranging patterns, we conducted a series of playback experiments to categorize the reactions of female elephants to the contact calls of other females in the population with which they had associated to varying degrees. We use this information to evaluate the extent to which female subjects are capable of recognizing others in the population through contact calls.

\section{METHODS}

\section{Study Population}

We conducted the study in Amboseli National Park, Kenya, where demographic records have been collected since 1972 on a population of elephants that currently numbers 988 individuals. The park encompasses $390 \mathrm{~km}^{2}$ and covers a varied ecosystem including open grassland sparsely scattered with Acacia trees, dense patches of palms, permanent and semipermanent areas of swamp and the seasonally flooded bed of Lake Amboseli; further details of the ecology of the area are given elsewhere (e.g. Moss \& Poole 1983). All the females and males in the population are recognized from a combination of natural features, particularly patterns of tears, holes and veins in the ears, and ear and tusk size and shape (Moss 1996).

Female and male elephants have very different patterns of social organization. A female's immediate social partners consist of her dependent offspring and the other members of her family unit (Moss \& Poole 1983). Association data on females for which full life histories are known (those born in or after 1972) indicate that family units are normally composed of close matrilineal relatives (mean number of adult females per family unit during this study \pm SD was $6 \pm 4$ ). A female's most frequent associates outside of her family unit are the members of other family units that belong to her bond group. Bond groups are defined by the regular association patterns of their component families and the fact that individual members frequently engage in 'greeting' displays when they meet after a period of separation. Not all family units form bond groups with others in the population (44\% of family units had bond groups during this study), but where these exist they are normally composed of two or three families each. Over and above this level of grouping, particular sets of family units tend to share the same feeding areas and Moss \& Poole (1983) called these associations 'clans'. However, because individual families range widely, particularly during the rainy seasons (November-December and March-May), they also come into contact with members of other clans. In this paper, levels of association between family units are expressed as mathematical association indices (see below) rather than by apparent clan membership. In contrast to females, males tend to live fairly solitary lives after independence and socialize only in loose male bachelor groups or in transitory encounters with female family units (Moss \& Poole 1983; Poole 1995). Because of these differences in social relationships, this paper focuses exclusively on the signalling and social behaviour of females.

\section{Association Indices}

We obtained data on the ranging and association patterns of the female study animals from regular monitoring of elephant family units carried out 6 days per week. These long-term records include the location and composition of each family sighted. Association indices were calculated from these data for the period January 1992 to May 1996 as: $N_{\mathrm{AB}} /\left(N_{\mathrm{A}}+N_{\mathrm{B}}+N_{\mathrm{AB}}\right)$ where $N_{\mathrm{AB}}=$ number of times families $\mathrm{A}$ and $\mathrm{B}$ are sighted in association; $N_{\mathrm{A}}=$ number of times $\mathrm{A}$ is sighted without $\mathrm{B} ; N_{\mathrm{B}}=$ number of times B is sighted without A (Martin \& Bateson 1993). Families were deemed to be in association when they were sighted in the same or adjacent $1-\mathrm{km}^{2}$ grid in the same 2 -h period. This criterion for association provides a good indication of the extent to which family units would have encountered each other directly and allows for association by means of signal recognition when individuals are out of sight of each other. 


\section{Sound Recording and Playback Equipment}

All contact calls used in playback experiments were recorded from known adult female elephants in the study area. We recorded contact calls on digital audiotape using equipment specialized for low-frequency recording: a Sennheiser MKH 110 microphone linked to a Sony TCD D10 DAT recorder with DC modification, which gave a frequency response for recording that could extend to $0 \mathrm{~Hz}$ (DC). The use of a filter in the power supply for the microphone (Audio Engineering Ltd, Cambridge, U.K.) meant that, in reality, frequencies below $5 \mathrm{~Hz}$ were usually filtered out. The system for playback was composed of a custom-built sixth-order bass box loudspeaker with two sound ports (see McComb 1996) linked to either a Sony XM-4020, Kenwood KAC 923 or Kicker Impulse 1252 xi power amplifier and a Sony TCD D10 (with DC modification) or HHb PortaDAT PDR 1000 DAT recorder. This playback system gives a lower frequency limit of $10 \mathrm{~Hz}$ and a response that is flat $\pm 4 \mathrm{~dB}$ from ca. $15 \mathrm{~Hz}$ on one sound port and ca. $20 \mathrm{~Hz}$ on the other.

\section{Protocol for Playback Experiments}

We used recordings of contact calls from 12 different adult females as playback stimuli. An adult female was taken to be one that has reached 11 years old, the mean age of first conception for the population (C. Moss, personal observation). All the calls we used had been recorded at distances of less than $30 \mathrm{~m}$ from the caller in conditions of low air turbulence. The playbacks described below were all conducted between June 1993 and May 1996, except for one (to test long-term memory for an individual's contact call, see below) conducted in January 1998. The subjects for any particular playback consisted of part or all of a known family unit and playbacks were confined to situations where the subjects were within their home range and where the individual whose call was to be played was not found within $2 \mathrm{~km}$ of the subjects; females from 27 different families served as subjects. In each playback we played a single contact call at peak sound pressure levels of $105 \mathrm{~dB}$ (referenced to $20 \mu \mathrm{Pa}$ ), SD $1 \mathrm{~dB}$, at $1 \mathrm{~m}$ (corresponding to the natural volume of a medium to loud contact call) from a Landrover vehicle that was located $100 \mathrm{~m}$ from the subjects. Sound pressure levels were measured with a CEL$414 / 3$ sound level meter. The vehicle was positioned at right angles to the direct line of sight to the elephants to enable the call to be played while the elephants were monitored from the windows on the driver's side; vocalizations were played through the rear door of the vehicle, so that the axis of playback was the same as the axis of the vehicle, that is, at right angles to the direct line of sight to the elephants. To prevent habituation, playbacks to the same family unit were always separated by a minimum of 1 week.

Responses to playback were observed through binoculars and recorded on videotape. Out of a range of behaviours monitored during playback experiments (see also: McComb 1996), we used the following behaviours to classify subjects' reactions.
(1) Listening: subjects hold ears in a stiff extended position.

(2) Contact calling: subjects give at least one contact call, usually preceded and followed by periods of listening.

(3) Approach to loudspeaker: subjects move towards the loudspeaker, often smelling the ground and air as they do so, pass level with it (crossing the axis of playback described above) and move into the area of ground beyond.

(4) Increase in group cohesion: subjects become agitated and bunch together so that the diameter of the whole group, or of constituent subgroups, decreases; calves in particular tend to move closer to adults. Changes in group cohesion were assessed visually by two observers during playback and then rescored on the video record where interelephant distances could be estimated in terms of elephant body lengths.

(5) Avoidance behaviour: subjects change direction to walk continuously away from the loudspeaker.

\section{Testing the Extent of Social Recognition}

To investigate the extent to which adult females could recognize others in the population through contact calls, we systematically played subjects recordings of contact calls from family members, members of family units in their bond group, and members of family units in the population that were further removed socially than bond group members; the latter associated with the subjects to varying extents that were indicated by the association index between the family unit of the subjects and the family unit of the caller.

Two specific comparisons were performed.

(1) To test whether subjects could discriminate the calls of members of their own family unit or bond group from those of other individuals, we compared their responses to calls from family unit and bond group members (mean association index \pm SD for bond groups $0.563 \pm 0.181$ ) with their responses to calls from members of other family units in the population that did not belong to these categories. Playback experiments were conducted on 29 independent groups of subjects. Playback of the same individual's call could represent a family/bond group member or a nonfamily/bond group member depending on the identity of the subjects.

(2) To test whether subjects were capable of vocal recognition beyond the level of family/bond group, we compared their responses to calls from members of other family units in the population that they encountered frequently with their responses to calls from members of other family units in the population that they encountered infrequently. For this comparison, 24 playbacks were given in matched pairs to 12 specific family units; each family of subjects was played the call of a member of a family unit that had a high association index with them and the call of a member of a family unit that had a low association index with them. The same adult females were present in each of the two playbacks which were always separated by at least 1 week and given in random 
order; playbacks were given only when all the calves in the subjects' family unit were at least 1 month old as behavioural observations and initial playback trials suggested that females are more agitated by the presence of nonfamily/bond group members when very small calves are present in their family unit. Playback of the same individual's call could represent a high association index family or a low association index family depending on the identity of the subjects. The mean association index \pm SD between the subjects and the family units in the high association index category was $0.077 \pm 0.036$ and between the subjects and the family units in the low association index category $0.023 \pm 0.013$; full details of the association indices involved are given in the Results.

For subjects to succeed at the discrimination task above, that is, to distinguish calls of family units that had high association indices with them from family units that had low association indices with them in the paired playbacks, they would at least require knowledge of the category of callers in the population represented by the sample of high association index families in our experiment. We estimated the number of family units represented in this category by: (1) determining statistically whether the subjects could perform the discrimination; (2) calculating the association indices between each family unit of subjects that could perform the discrimination and every other family unit in the population; and (3) determining the number of family units with which each of these families associated at least as often as with the high association family whose call they had discriminated, that is, at indices greater than or equal to their association index with this family.

\section{Long-term Memory of an Individual's Call}

Two natural events provided us with the opportunity to investigate whether adult females can retain a long-term memory of others' calls, one in a situation where they have had no contact with the caller for a long period and the other in a situation where they have had some contact with her.

(1) One adult female (aged 15 years), whose contact call we had recorded, died during the study. We monitored the responses of members of her family unit to her call on two occasions, one 3 months (May 1996) and one 23 months after her death (January 1998).

(2) One adult female was unusual in leaving her original family unit in 1983 to join another family unit in the population, although the two family units involved continued to have a significant level of contact (association index January 1992-May 1996: 0.140). In 1995, we played a call recorded from the female that had changed family units to the members of her original family unit and monitored their responses.

\section{RESULTS}

\section{Discrimination at Family/Bond Group Level}

Subjects reacted differently to playbacks of calls from members of their own family unit or bond group versus
Table 1. Responses of subjects to playbacks of calls from female family/bond group members versus females that did not belong to these categories

\begin{tabular}{|lcc|}
\hline & \multicolumn{2}{c|}{ Response } \\
\cline { 2 - 3 } Call played & Present & Absent \\
\hline & & \\
Contact calling & 10 & 3 \\
$\quad$ Family/bond group member & 0 & 16 \\
$\quad$ Not family or bond group member & & \\
Approach to loudspeaker & 6 & 7 \\
$\quad$ Family/bond group member & 0 & 16 \\
Not family or bond group member & & \\
\hline
\end{tabular}

Responses are categorized according to the presence or absence of contact calling and approach to the loudspeaker.

calls from members of other family units in the population that did not belong to these categories. Contact calling and approaches to the loudspeaker were exclusively associated with playbacks of family unit or bond group members (Table 1 ). In response to playbacks of calls of family or bond group members, subjects were significantly more likely to give contact calls (Table 1); Fisher's exact probability test: $N=29, P<0.001$, two tailed), and to approach the loudspeaker (Table 1; Fisher's exact probability test: $N=29, P=0.004$, two tailed), than in response to playbacks of calls from other family units not in these categories. Of the two incidences where neither contact calling nor approach to the loudspeaker were obtained in response to playback of a family or bond group member's call, one was in response to playback of a family member's call (out of seven playbacks of family members' calls in this category) and one was in response to playback of a bond group member's call (out of six playbacks of bond group members' calls in this category).

\section{Discrimination Beyond Family/Bond Group Level}

Subjects gave significantly different responses to playbacks of calls from members of family units (outside of the family/bond group category) with which they had a high association index than to those with which they had a low association index. Playbacks of calls from high association index families generally resulted in listening only (11 of 12 cases; Table 2 ), whereas playbacks of calls from low association index families generally resulted in an increase in group cohesion or avoidance behaviour (11 of 12 cases; Table 2). Overall, subjects became more agitated in response to playbacks of low association index families than to playbacks of high association index families, as indicated by increases in group cohesion and avoidance (sign test: $N=10$ ( 2 ties), $P=0.002$, two tailed).

\section{Overall Vocal Recognition Capabilities}

As discussed in the Methods, in order for subjects to accomplish the discrimination task described above they 
Table 2. Responses to paired playbacks of calls from females that had high versus low association indices with the subjects

\begin{tabular}{|c|c|c|}
\hline $\begin{array}{l}\text { Family of } \\
\text { subjects }\end{array}$ & $\begin{array}{l}\text { Call from high } \\
\text { association index } \\
\text { family }\end{array}$ & $\begin{array}{c}\text { Call from low } \\
\text { association index } \\
\text { family }\end{array}$ \\
\hline$C A$ & $\begin{array}{l}\text { Listen only } \\
(0.064)\end{array}$ & $\begin{array}{c}\text { Bunch and retreat } \\
(0.007)\end{array}$ \\
\hline$C B$ & $\begin{array}{l}\text { Listen only } \\
(0.037)\end{array}$ & $\begin{array}{l}\text { Bunch } \\
(0.014)\end{array}$ \\
\hline EB & $\begin{array}{l}\text { Listen only } \\
(0.097)\end{array}$ & $\begin{array}{c}\text { Bunch and retreat } \\
(0.033)\end{array}$ \\
\hline FB & $\begin{array}{l}\text { Listen only } \\
(0.081)\end{array}$ & $\begin{array}{l}\text { Bunch } \\
(0.040)\end{array}$ \\
\hline GB & $\begin{array}{l}\text { Listen only } \\
(0.065)\end{array}$ & $\begin{array}{l}\text { Bunch } \\
(0.021)\end{array}$ \\
\hline KB & $\begin{array}{c}\text { Bunch and retreat } \\
\qquad(0.078)\end{array}$ & $\begin{array}{c}\text { Bunch and retreat } \\
\qquad(0.046)\end{array}$ \\
\hline LA & $\begin{array}{c}\text { Listen only } \\
(0.059)\end{array}$ & $\begin{array}{l}\text { Bunch } \\
(0.008)\end{array}$ \\
\hline LB & $\begin{array}{l}\text { Listen only } \\
(0.170)\end{array}$ & $\begin{array}{c}\text { Bunch and retreat } \\
\qquad(0.019)\end{array}$ \\
\hline OA & $\begin{array}{l}\text { Listen only } \\
(0.049)\end{array}$ & $\begin{array}{l}\text { Bunch } \\
(0.013)\end{array}$ \\
\hline $\mathrm{OB}$ & $\begin{array}{l}\text { Listen only } \\
(0.037)\end{array}$ & $\begin{array}{c}\text { Bunch } \\
(0.034)\end{array}$ \\
\hline PC & $\begin{array}{l}\text { Listen only } \\
(0.079)\end{array}$ & $\begin{array}{c}\text { Bunch and retreat } \\
(0.019)\end{array}$ \\
\hline TA & $\begin{array}{l}\text { Listen only } \\
(0.104)\end{array}$ & $\begin{array}{l}\text { Listen only } \\
(0.022)\end{array}$ \\
\hline
\end{tabular}

The association index between the subjects' family and family whose call was played is given in parentheses.

would at least require knowledge of the category of callers in the population represented by the sample of high association index families in our experiment. Ten of 12 families of subjects discriminated between high and low association index families, with responses of 'listen only' to high association index callers and 'bunch' or 'bunch and retreat' to low association index callers (Table 2).

The two families that failed to discriminate gave the same response to the two playbacks, in one case by giving a 'listen only' response to both and in the other by giving a 'bunch and retreat' response to both (Table 2 ). It could be that these tied responses indicate that the subjects involved had knowledge of both categories and neither category of callers, respectively, but rather than bias the results through potentially erroneous assumptions we excluded them from our estimation of the total number of families in the population whose calls subjects were familiar with.

We estimated the total number of families in the population whose calls subjects were familiar with by examining the number of family units with which each of the 10 families that did discriminate high from low association index family calls in playbacks associated at least as often as with the high association index family whose call they had discriminated. This may be a minimum estimate because family units represented in the high association index category were a sample selected by us and subjects could have been familiar with the calls of additional family units with lower association indices than those that we included. We found that the mean \pm SD number of family units in the population with which these subjects associated at least as often as with the high association index callers in playback experiments was $14 \pm 9$, which included a mean \pm SD of $101 \pm 65$ adult females.

\section{Long-term Memory of Individual's Call}

Playback of the call from the female that had died, to her family unit, elicited contact calling 3 months after her death, and contact calling and approach to the loudspeaker 23 months after her death. Playback of the call from the female that had changed family units, to her original family unit 12 years after the transfer had taken place, elicited contact calling.

\section{DISCUSSION}

Our experiments showed that female African elephants not only give a characteristic reaction to the contact calls of family or bond group members, but can also discriminate between the calls of less frequent associates, distinguishing between the calls of individuals in this category with which they have higher versus lower association indices. Subjects could not have performed this discrimination unless they were familiar with calls from the category of females in the population represented by the sample of high association index families in our experiment. When we estimated the number of families in this proportion of the population by examining the number of family units with which subjects associated at least as often as with the high association index family whose call they had discriminated in playbacks, we found that adult females in Amboseli are potentially familiar with the contact calls of a mean of 14 different families (including around 100 adult females). Studies indicating that individuals are familiar with the calls of companions within the same social group, kin and territorial neighbours are now fairly common in the literature on mammals (e.g. Waser 1977; Cheney \& Seyfarth 1982; Price et al. 1990; McComb et al. 1993; Barfield et al. 1994; Rendall et al. 1996). However, we know of no previous demonstration that networks of vocal recognition may be as large as those indicated here.

Playbacks of calls from family or bond group members generated a strong positive response characterized by contact calling and approaches to the area whence the call came. Under normal circumstances, such affiliative behaviour would be likely to bring the signaller and receivers into contact. This confirms earlier behavioural observations that contact calls are used by females to locate other members of their family unit (Poole et al. 1988) and shows that bond group members are also located in this way. Rather than generating calling and approach, playbacks of calls from females that did not share the same family or bond group as the subject elicited two further types of reaction that were quite distinct in nature and depended on the association index between the caller and the subjects. In playbacks of calls 
from high association index families, subjects tended to remain relaxed (listening briefly to the calls and then resuming preplayback behaviours), whereas they typically became agitated in response to calls from low association index families (bunching up into defensive formation and sometimes moving away from the stimulus). The relaxed response to calls from high association index families supports the hypothesis that these families are being identified as having been encountered before. A degree of toleration of high association index families could be advantageous, as families with this level of association often share the same feeding grounds. In comparison, the characteristic responses given to calls from low association index families suggests that these families might have been viewed as potential aggressors. The detection of less familiar females (low association index families) would be particularly beneficial if individuals from this section of the population were more likely to initiate agonistic disputes or harass young calves, both of which behaviours have been observed in the Amboseli population (C. Moss, personal observation; K. McComb \& S. Sayialel, personal observation).

Dunbar (1993a) described an intermediate level of grouping in humans that is identifiable both in huntergatherer and Westernized societies as a 'subset of the population that interacts on a sufficiently regular basis to have strong bonds based on direct personal knowledge'. There are usually between 100 and 200 individuals in this grouping which he termed a 'clan' (Dunbar 1993a; see also Dunbar 1993b, 1995). Dunbar suggested that knowledge of individuals outside of the clan grouping in hunter-gatherer societies may typically be based on gross categories (a 'them' and 'us' distinction) rather than on identifying particular individuals (Dunbar 1993a). The responses that we obtained to playbacks of calls from high versus low association index families may also indicate a 'them' versus 'us' distinction. However, the extent of social knowledge that characterizes relationships between individuals that remain relaxed in response to each others' calls (i.e. within the high association index category) is difficult to assess and while our results are consistent with the possibility that individual recognition' could have taken place, they are also consistent with vocal recognition occurring at lower levels.

The term individual recognition is appropriate for instances where a signal has not only been recognized (i.e. identified as encountered before) but also perceived as belonging to a particular known individual (see similar arguments by Beer 1970 for individual recognition and Barnard 1991 for kin recognition). Several different levels of vocal recognition could explain our results. First, each of the individuals included in the section of the population discriminated as familiar could be individually recognized by our subjects, but elucidation of the mechanism of recognition was not the focus of our study and additional tests would be necessary to identify this level of recognition unambiguously. Second, instead of recognizing each of these individuals specifically, subjects could have recognized their many different voices as having been encountered before. Third, acoustic cues advertising family identity could have allowed subjects to perform the perceptual discriminations described in this paper by learning to recognize vocal characteristics of the families that they associated with most frequently, rather than becoming familiar with the calls of every adult female contained in these families; some nonhuman primate vocalizations contain acoustical signatures that are sufficiently distinct to advertise the matrilineal kin group membership of the caller (Gouzoules \& Gouzoules 1990; see also Hauser 1991) and kin recognition on the basis of these features has been demonstrated in rhesus monkeys, Macaca mulatta (Rendall et al. 1996). Acoustical analyses have shown that there are sufficient cues in the contact calls of adult female elephants to advertise their individual identity (K. McComb, unpublished data). There are, however, no signs that the calls of members of the same family converge, although this possibility cannot be ruled out. Irrespective of which of the mechanisms of vocal recognition described above explains the responses that we observed, our results indicate that females have the ability to identify as familiar the calls of a very substantial number of the conspecifics that they encounter while ranging widely.

Our playbacks of a female's call to other members of her family unit 3 and 23 months after her death provided some anecdotal evidence that adult females can maintain a memory of an individual's call characteristics even when that individual is not encountered for long periods, but further experiments would be necessary before firm conclusions can be drawn. Even the playback given when 23 months had elapsed since the female's death produced a strong affiliative response from members of her family unit (characteristic of playbacks of family and bond group members), which approached the loudspeaker and repeatedly gave contact calls. Contact calling was also obtained in response to playback of the female that had changed family units, when members of her family unit were played her call 12 years after the transfer was complete. In this case, however, contact between the two family units involved in the 12 years since the transfer will have facilitated maintenance of a memory for the call. Memory of the vocalizations of familiar conspecifics for periods of up to a year has been demonstrated in great tits, Parus major (McGregor \& Avery 1986), and hooded warblers, Wilsonia citrina (Godard 1991). In mammals, there appear to be no systematic demonstrations that the memory of social companions' calls are retained during long periods of absence, although there is some indication that Asian elephants, Elephas maximus, may have a long-term memory for olfactory signals (Rasmussen 1995).

In conclusion, our results indicate that female elephants have unusually large networks of vocal recognition. These results should focus attention on the opportunities that species with fluid systems of social organization have for developing a knowledge of the signals of a widespread population of conspecifics, particularly where individuals are long lived and social knowledge can be accumulated over considerable time periods. Quantitative studies of the extent of vocal recognition networks in cetaceans and primates, where large networks would be predicted, are warranted. Finally, it is 
now important to investigate the relative effects of fluidity and other factors that could influence an individual's opportunities for learning to recognize the signals of others on vocal recognition abilities, and to examine the fitness consequences of having extensive social knowledge.

\section{Acknowledgments}

This study was funded by Royal Society Research Grant number 13986 and BBSRC Research Grant 85/S07659 (both to K.M.). Additional financial support and/or equipment was provided by the African Wildlife Foundation, the Association for the Study of Animal Behaviour, Newnham College (Cambridge), NERC small project grant GR9/1191, the Nuffield Foundation and the Tusk Trust. We are grateful to the Kenyan Office of the President and Kenya Wildlife Services for permission to conduct the work in Amboseli National Park and to Katito Sayialel and Norah Njiriana for assistance with fieldwork. Barbie Allen provided much appreciated logistic support, and Dorothy Cheney, Sarah Durant, Aubrey Manning, Phyllis Lee, David Reby, Stuart Semple and two anonymous referees made valuable comments on the manuscript.

\section{References}

Barfield, C. H., Tangmartinez, Z. \& Trainer, J. M. 1994. Domestic calves (Bos taurus) recognize their own mothers by auditory cues. Ethology, 97, 257-264.

Barnard, C. 1991. Kinship and social behaviour: the trouble with relatives. Trends in Ecology and Evolution, 6, 310-312.

Beer, C. G. 1970. Individual recognition of voice in the social behaviour of birds. Advances in the Study of Behavior, 3, 27-74.

Cheney, D. L. \& Seyfarth, R. M. 1982. Recognition of individuals within and between groups of free-ranging vervet monkeys. American Zoologist, 22, 519-529.

Dunbar, R. I. M. 1993a. Coevolution of neocortical size, group size and language in humans. Behavioral and Brain Sciences, 16, 681-694.

Dunbar, R. I. M. 1993b. On the origins of language: a history of constraints and windows of opportunity. Behavioral and Brain Sciences, 16, 721-729.

Dunbar, R. I. M. 1995. Neocortical size and language. Behavioral and Brain Sciences, 18, 388-389.

Ford, J. K. B. 1991. Vocal traditions among resident killer whales (Orcinus orca) in coastal waters of British Columbia. Canadian Journal of Zoology, 69, 1451-1483.

Garstang, M., Larom, D., Raspet, R. \& Lindeque, M. 1995. Atmospheric controls on elephant communication. Journal of Experimental Biology, 198, 939-951.

Gouzoules, H. \& Gouzoules, S. 1990. Matrilineal signatures in the recruitment screams of pigtail macaques, Macaca nemestrina. Behaviour, 115, 327-347.

Godard, R. 1991. Long-term memory of individual neighbours in a migratory songbird. Nature, 350, 228-229.

Hauser, M. D. 1991. Sources of acoustic variation in rhesus macaque, Macaca mulatta, vocalizations. Ethology, 89, 29-46.

Langbauer, W. R., Payne, K. B., Charif, R. A., Rapaport, L. \& Osborn, F. 1991. African elephants respond to distant playbacks of low-frequency conspecific calls. Journal of Experimental Biology, 157, 35-46.

Larom, D., Garstang, M., Payne, K., Raspet, R. \& Lindeque, M. 1997a. The influence of surface atmospheric conditions on the range and area reached by animal vocalisations. Journal of Experimental Biology, 200, 421-431.

Larom, D., Garstang, M., Lindeque, M., Raspet, R., Zunckel, M., Hong, Y., Brassel, K. \& O'Beirne, S. 1997b. Meteorology and elephant infrasound at Etosha National Park, Namibia. Journal of the Acoustical Society of America, 101, 1710-1717.

McComb, K. 1996. Studying vocal communication in elephants. In: Studying Elephants (Ed. by K. Kangwana), pp. 112-119. Nairobi: African Wildlife Foundation.

McComb, K., Pusey, A., Packer, C. \& Grinnell, J. 1993. Female lions can identify potentially infanticidal males from their roars. Proceedings of the Royal Society of London, Series B, 252, 59-64.

McGregor, P. K. 1993. Signalling in territorial systems: a context for individual identification, ranging and eavesdropping. Philosophical Transactions of the Royal Society of London, Series B, 340, 237-244.

McGregor, P. K. \& Avery, M. I. 1986. The unsung songs of great tits (Parus major): learning neighbours' songs for discrimination. Behavioral Ecology and Sociobiology, 18, 311-316.

McGregor, P. K. \& Dabelsteen, T. 1996. Communication networks. In: Ecology and Evolution of Acoustic Communication in Birds (Ed. by D. E. Kroodsma \& E. H. Miller), pp. 409-425. New York: Cornell University Press.

Martin, P. \& Bateson, P. 1993. Measuring Behaviour: an Introductory Guide. 2nd edn. Cambridge: Cambridge University Press.

Moss, C. J. 1996. Getting to know a population. In: Studying Elephants (Ed. by K. Kangwana), pp. 58-74. Nairobi: African Wildlife Foundation.

Moss, C. J. \& Poole, J. H. 1983. Relationships and social structure of African elephants. In: Primate Social Relationships: an Integrated Approach (Ed. by R. A. Hinde), pp. 315-325. Oxford: Blackwell Scientific.

Nishida, T. \& Hiraiwa-Hasegawa, M. 1986. Chimpanzees and bonobos: cooperative relationships among males. In: Primate Societies (Ed. by B. B. Smuts, D. L. Cheney, R. M. Seyfarth, R. W. Wrangham \& T. T. Struhsaker), pp. 165-177. Chicago: University of Chicago Press.

Otter, K., McGregor, P. K., Terry, A. M. R., Burford, F. R. L., Peake, T. M. \& Dabelsteen, T. 1999. Do female great tits Parus major assess males by eavesdropping? A field study using interactive playback. Proceedings of the Royal Society of London, Series $B$, 266, 1305-1309.

Poole, J. H. 1995. Sex differences in the behaviour of African elephants. In: The Differences Between the Sexes (Ed. by R. V. Short \& E. Balaban), pp. 331-346. Cambridge: Cambridge University Press.

Poole, J. H., Payne, K., Langbauer, W. R. Jr \& Moss, C. J. 1988. The social contexts of some very low frequency calls of African elephants. Behavioral Ecology and Sociobiology, 22, 385-392.

Price, K., Boutin, S. \& Ydenberg, R. 1990. Intensity of territorial defense in red squirrels: an experimental test of the asymmetric war of attrition. Behavioral Ecology and Sociobiology, 27, 217-222.

Rasmussen, L. E. L. 1995. Evidence for long-term chemical memory in elephants. Chemical Senses, 20, 237-237.

Rendall, D., Rodman, P. S. \& Emond, R. E. 1996. Vocal recognition of individuals and kin in free-ranging rhesus monkeys. Animal Behaviour, 51, 1007-1015.

Waser, P. M. 1977. Individual recognition, intragroup cohesion and intergroup spacing: evidence from sound playback to forest monkeys. Behaviour, 60, 28-74. 